\title{
Global climate cycles and cyclones: consequences for rainfall patterns and lemur reproduction in southeastern Madagascar
}

\author{
AMY E. DUNHAM*, ELIZABETH M. ERHART $\dagger$ and PATRICIA C. WRIGHT \\ *Department of Ecology and Evolutionary Biology, Rice University, 6100 Main St., Houston, TX 77005, USA, †Department of \\ Anthropology, Texas State University, 601 University Drive, San Marcos, TX 78666, USA, †Department of Physical Anthropology, \\ Stony Brook University, Stony Brook, NY, 11794, USA
}

\begin{abstract}
Most studies that examine the influence of climatic change on flora and fauna have focused on northern latitudes; however, there is increasing recognition that tropical regions are also being affected. Despite this, regions such as Madagascar, which are rich in endemic biodiversity but may have low adaptive capacity to climatic change, are poorly represented in studies examining the effects of climate variability on biota. We investigated how El Niño Southern Oscillations (ENSO) influence precipitation patterns in the rainforest region of southeastern Madagascar (1962-2006) and then constructed models to assess the potential contribution of climatic variables on the reproductive parameters of the Milne Edward's sifaka, a threatened lemur species (Propithecus edwardsi), over a 20-year period. The Southern Oscillation Index of sea surface temperature (SST) anomalies in the tropical Pacific was associated with precipitation patterns including wetter wet seasons during warmer phases and drier dry seasons following cooler phases. The bestsupported models of lemur fecundity (female offspring per female that survive to 1 year of age per year) included cyclone presence during gestation and ENSO phase before conception and during the first 6 months of life. Models also suggested that heavy rains during gestation may limit birth rates and that prolonged drought during female lactation may limit first year offspring survival; although these variables were given little importance for predicting overall fecundity relative to ENSO phases and cyclone presence. Our results linking lemur reproduction with climatic variability suggest that climatic changes may be an additional threat to Madagascar's unique and already endangered flora and fauna. The association between precipitation in southeastern Madagascar and SST anomalies in the tropical Pacific suggests that dynamics of wildlife populations even in tropical areas such as Madagascar can be affected by global climate cycles making them potentially vulnerable to global climate change.
\end{abstract}

Keywords: climate change, cyclone, demography, drought, ENSO, Madagascar, Propithecus edwardsi, rainfall, rainforest, sifaka

Received 1 December 2009 and accepted 30 December 2009

\section{Introduction}

An increasing recognition of pressures facing wildlife populations from global climate change and habitat degradation has led to a growing interest in quantitative studies of the factors affecting the distribution and abundance of rare species (Walther et al., 2002; Adahl et al., 2006; Sagarin et al., 2006). Understanding how demographic parameters are influenced by temporal environmental variability is critical for interpreting changes in animal populations (Caswell, 2001) and in predicting how species will respond to future climate change scenarios.

Although most studies that examine climate change impacts on flora and fauna focus on northern latitudes,

Correspondence: A. E. Dunham, tel. + 1713348 2792, fax + 1713 348 5232, e-mail: aed4@rice.edu the tropics are being recognized as an important element in the dynamic process of global climate change. There is a recent recognition that tropical forest communities have responded both to global climate phenomena in the prehistoric past (Thomson et al., 2003; Marchant \& Hooghiemstra, 2004) and to atmospheric and climatic changes occurring recently (Malhi \& Wright, 2004; Harris et al., 2008). Understanding the patterns of climatic change across the tropics and its potential impacts on flora and fauna has been difficult because of the paucity of long-term records (Malhi \& Wright, 2004). Additionally, most tropical research on effects of climate change has focused on the Amazon basin (e.g. Harris et al., 2008; Huntingford et al., 2008), with limited work in Old World tropical forests (Dixon et al., 2003) where impacts are likely to differ due to geographical differences. Indeed, existing climate models suggest pronounced climate change is expected 
to occur in Madagascar by 2050 with increasing austral summer rainfall (January-April) and drier austral winters (July-September) in the southeastern region of Madagascar (Hannah et al., 2008; Tadross et al., 2008). Significant increases in variability of annual rainfall has also been observed in Madagascar over the last century (Ganzhorn, 1995).

Nearly half of the world's vascular plant species and one-third of terrestrial vertebrates are held within the 25 global 'hotspots' of biodiversity (Myers et al., 2000). More than half of these hotspots consist of tropical rainforest and we know very little about how global climate change is likely to affect the ecosystems and threatened wildlife within by these areas (Brooks et al., 2002). This is especially concerning since tropical rainforest is now limited to only $1.4 \%$ of the Earth's landmass. One of the hotspots containing the most endemic families and genera in the world is within the southeastern rainforest of Madagascar (Myers et al., 2000; Kremen et al., 2008). Madagascar is home to more endemic families and genera than any other conservation 'hotspot' in the world, and high rates of habitat loss and other anthropogenic disturbances severely threaten native species (Myers et al., 2000). Over $80 \%$ of the forest cover has already been lost and the populations of many remaining species are small and fragmented (Whitmore, 2000). While there has been much research discussing the effects of habitat loss and hunting pressures on the viability of wildlife populations in Madagascar (Sommer \& Hommen, 2001; Irwin et al., 2005; Lehman et al., 2005, 2006; Mittermeier et al., 2006), the confounding effects of recent climate change and global climate cycles such as El Niño Southern Oscillations (ENSO) have rarely been broached (Wright, 2006; Raxworthy et al., 2008; but see Dunham et al., 2008).

ENSO indirectly drives rainfall variability in areas around the Indian Ocean basin such as Madagascar. Rainfall is affected by sea surface temperatures (SSTs) in the basin (Klein et al., 1999) that are remotely forced by SST anomalies in the equatorial eastern Pacific (i.e. ENSO) (Venzke et al., 2000; Lau \& Nath, 2003; Shinoda et al., 2004), however, climatic effects of ENSO have not been well established for Madagascar (Ingram \& Dawson, 2005). Although some studies have suggested that El Niño events are associated with drought (Thomson et al., 2003; Ingram \& Dawson, 2005), others have reported that El Niño coincides with wetter conditions (Jury, 2003). This discrepancy may be because the climate of Madagascar is highly variable internally due to its large size and topographic diversity. Regardless, the high frequency of ENSO in the last few decades has raised questions about how human-induced climate change is affecting or will affect the frequency of ENSO (Meehl et al., 2006; Latif \& Keenlyside, 2009). The prospect of climatic changes including potentially increasing ENSO events in Madagascar is daunting given the immediacy and severity of other anthropogenic threats to its biodiversity (Harper et al., 2008; Kremen et al., 2008).

Lemurs may be particularly sensitive to changes in climatic variables because the neuroendocrine processes controlling their physiological and behavioral reproductive events appear to be strongly dependent on photoperiod (Van Horn \& Eaton, 1979). In the southeastern rainforest of Madagascar, this strict seasonality results in weaning schedules of diurnal lemurs to coincide with a seasonal peak in fruit and young leaf availability (Wright, 1999, 2006), suggesting the potential importance of reproductive timing to infant survival for a whole guild of arboreal primates. We assembled 49 years of data of ENSO cycles and regional rainfall patterns in southeastern Madagascar and synthesized 20 years of demographic data on an endangered lemur of the southeastern rainforests, Propithecus edwardsi (Milne Edwards' sifaka) (Dunham et al., 2008; Erhart \& Overdorff, 2008b; Wright, 1995). With these data, we evaluated associations between variables to address the following questions: (1) How are rainfall patterns in southeastern Madagascar associated with ENSO? (2) How are precipitation patterns, ENSO phases, and cyclones associated with reproductive parameters of $P$. edwardsi? (3) What is the direction and intensity of these associations?

\section{Materials and methods}

\section{Climatic variables}

Average monthly rainfall data for Ranomafana, Madagascar $\left(47^{\circ} 18^{\prime}-47^{\circ} 37^{\prime} \mathrm{E}\right.$ and $\left.21^{\circ} 02^{\prime}-21^{\circ} 25^{\prime} \mathrm{S}\right)$ were obtained from Madagascar's National Weather Station Records (Antananarivo, Madagascar) for the village of Vohiparara, outside of Ranomafana National Park (RNP) from 1962 to 1986, and from the research station of RNP from 1989 to 2006. These data were used to examine the relationship of rainfall patterns and ENSO and lemur reproductive parameters. The Southern Oscillation Index (SOI) values were obtained from the Australian Bureau of Meteorology (http://www.bom.gov.au/climate/current/soihtm1.shtml), calculated as the monthly standardized anomaly of the mean sea level pressure difference between Tahiti and Darwin.

For selecting ENSO phases, we adopted the Japan Meteorological Agency (JMA) ENSO criteria, which is based on observed (1949-present) mean SST anomalies from the tropical Pacific Ocean (COAPS, 2008). The JMA index selects strong, well known ENSO events with a 5-month running mean of spatially averaged SST anomalies over the tropical Pacific: $4^{\circ} \mathrm{S}-$ $4^{\circ} \mathrm{N}, 150^{\circ} \mathrm{W}-90^{\circ} \mathrm{W}$ (Hanley et al., 2003). Years were assigned to warm-phase (El Niño), neutral-phase or cold-phase (La Niña or El Viejo) categories based on the JMA index, which categorizes years with anomalies of $\geq 0.5^{\circ} \mathrm{C}$, consecutively from October to December as warm phases and $\leq-0.5^{\circ} \mathrm{C}$ 
(October-December) as cold phases. Ranked ENSO phases ( $1=$ warm phase, $2=$ neutral and $3=$ cold phase $)$ were used in addition to SOI values to examine a possible relationship between strong anomalies and altered rainfall patterns in RNP.

Data on the number of cyclones making landfall in Madagascar from 1962 to 2004 were obtained through the African Desk of the NOAA Climate Prediction Center (http:/ / www.cpc. noaa.gov/products/african_desk/). Cyclone data were used to examine potential relationships with $\mathrm{SOI}$ and with lemur reproductive parameters.

\section{Demographic data}

P. edwardsi are found in the southeastern rainforests of Madagascar where they live in social groups of three to nine individuals with infants born in late June (Pochron \& Wright, 2003). Demographic data collected between 1986 and 2006 were collated from two long-term studies (for description see Erhart \& Overdorff, 1998; Wright, 1995) involving six groups of animals (120 individuals) in RNP, a 41300 ha protected area with elevations of 600-1500 m (Wright \& Andriamihaja, 2002). Four of the groups from one study (Wright, 1995) were adjacent to each other and individuals occasionally dispersed into the two adjacent groups of the other long-term study and vice versa (Erhart \& Overdorff, 1998) suggesting strong gene flow among study groups. Animals were habituated to human observation and marked with identification collars to allow routine surveys and observational follows. All births and deaths were recorded allowing for yearly estimates of birth rates and first year survival rates based on direct observations. Deaths of individuals under 1 year of age and dependant on maternal care were assumed when the infants disappeared from the group because they are not expected to be able to survive independently before weaning. Out of 30 infant deaths observed or assumed in the Wright (1995) study, five were observed or inferred predation events by fossa (Cryptoprocta ferox) and nine were observed or suspected infanticide cases (see Morelli et al., 2009). Because weather events can weaken individuals and make them more susceptible to predation, or alter immigration rates of individuals who may commit infanticide, all causes of death were included in the analysis. Because recognized marked individuals were followed regularly (see Pochron et al., 2004), mark recapture methods were not necessary to obtain vital rates.

We explored patterns linking rainfall patterns to lemur fecundity (number of female offspring per adult female surviving to 1 year of age per year) and its subcomponents, birth rate and first year survival. Determining sex of juveniles can be troublesome through observation alone. In cases where sex was unknown, parameters were estimated under the assumption of equivalent mortality levels among sexes and a $1: 1$ sex ratio at birth. Like most lemurs, P. edwardsi are sexually monomorphic in size (Dunham \& Rudolf, 2009) and a previous study of the same population (Dunham et al., 2008) showed no significant difference in survival to 1 year of age when offspring of known sex were compared (Student's $t$-test, $t=0.20, \mathrm{df}=17, P=0.842$ ). We focused on fecundity because population growth rate of this species has been shown to be sensitive to changes in this parameter (Dunham et al., 2008) and it may be the most sensitive parameter to environmental change (King et al., 2005). Fecundity and first year survival were arcsine square root transformed for normality.

\section{Statistical analyses}

For all correlations performed, we adjusted the degrees of freedom to account for the autocorrelations between years that violate the assumption of serial independence and overestimate the number of degrees of freedom (Bence, 1995; Pyper \& Peterman, 1998). The 'effective' number of degrees of freedom $N^{*}$ were calculated as

$$
\frac{1}{N^{*}} \approx \frac{1}{N}+\frac{2}{N} \sum_{j=1}^{N / 5} \frac{(N-j)}{N} \rho_{X X}(j) \rho_{Y Y}(j),
$$

where $N$ represents the sample size of years in the time series and $\rho_{X X}(j)$ and $\rho_{Y Y}(j)$ represent the autocorrelations present in the two series, $X$ and $Y$, at lag $j$ (Chelton, 1984). Adjusted degrees of freedom were then used to calculate an adjusted critical value for the cross-correlation coefficient, $r_{\text {crit }}$ with the equality

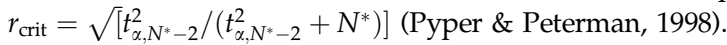

Generalized linear models of fecundity, and its subcomponents of birth rate and female first year survival, were constructed using Akaike's information criterion (AIC). We focused our environmental variables for the analysis on precipitation patterns during the wet and dry seasons because they are thought to be biologically relevant to the lemurs and are predicted to change with a changing climate (Dunham et al., 2008), as well as ENSO phase and cyclone presence. Variables included in the models were: (1) ENSO phase (based on JMA index), (2) average monthly dry season rainfall (July-October), (3) months of drought, defined as the number of months of below average dry season rain $(<150 \mathrm{~mm})$, (4) average monthly wet season rainfall (January-March), (5) months with extreme rain, defined as the number of months with rainfall $>550 \mathrm{~mm}$ (an arbitrary threshold level of rainfall determined as that occurring $\leq 10 \%$ of an average year) and (6) presence/absence of cyclones during the year. We used an information-theoretic approach (ITA) and constructed all possible configurations between the vital rates and time intervals of climatic variables thought to be biologically relevant. These time intervals of rainfall variables and cyclones included those overlapping gestation $(\mathrm{G})$ and lactation periods (L), and for annual ENSO conditions including conditions occurring the year before conception (A), the year including gestation and first 6 months (B) and the year including the second 6 months after birth (C). We used an ITA over a stepwise approach as the latter has been criticized for its bias in parameter estimation, inconsistent model selection algorithm, and inappropriate focus on a single best model (Whittingham et al., 2006). ITA avoids restricting ecological inference to only one model by allowing identification of competing models that may describe the data equally well. Model support in our analysis was measured by comparing differences in AIC scores (Burnham \& Anderson, 2002) and Akaike model weights (normalized relative likelihood values), which represent the likelihood of a model being true given that a true model is represented in the 
set of models. These tests were done using JMP ${ }^{\circledR} 8.0$ (SAS Institute, 2009, NY, USA. http://www.jmp.com).

\section{Results}

\section{ENSO and rainfall patterns}

Monthly precipitation in RNP is highly variable with a mean of $240 \mathrm{~mm}$ ( $\pm 198 \mathrm{~mm}$ ) and a median of $180 \mathrm{~mm}$ (Fig. 1a). Monthly rainfall ranged from the record high in February 1990 with $1200 \mathrm{~mm}$ to the record low of $10 \mathrm{~mm}$ in October 1996. The peak wet season runs from January to March, with an average monthly precipitation of $508 \mathrm{~mm}( \pm 199 \mathrm{~mm})$. The dry season peaks June-October and overlaps with the peak lactation period of P. edwardsi (Wright, 2006). Monthly rainfall during this dry period averages $143 \mathrm{~mm}( \pm 50 \mathrm{~mm}$ ).

Sustained negative values of the SOI often indicate El Niño episodes while sustained positive values often indicate La Niña episodes. In Madagascar's southeastern rainforest, monthly SOI values were negatively correlated with average monthly rainfall (Fig. 1b) (Spearman's $P=-0.37, \mathrm{df}=34, P=0.03)$ and the number of months of extreme rain $(>550 \mathrm{~mm})$ within a year (Spearman's $P=-0.40, \mathrm{df}=29, P=0.02)$. ENSO phases $(1=$ warm phase, $2=$ neutral, and $3=$ cold phase) were positively associated with the number of months of below average dry season rain $(<150 \mathrm{~mm})$ in the following year during July-October, the lemur's peak lactation period (Spearman's $P=0.43, \mathrm{df}=31, P=0.01$ ). Note that all degrees of freedom are adjusted to account for autocorrelations in data (Pyper \& Peterman, 1998).

\section{Birth rates}

Cyclones were noted to have a strong negative relationship with P. edwardsi birth rates (birth rates: $F_{1,14}=15.7$, $P=0.001$, Fig. 2) and were expected to be an important variable in describing birth rate variation. Four models of lemur birth rate had considerable support $\left(\Delta \mathrm{AIC}_{\mathrm{c}}<2\right)$, with little difference in the relative evidence ratios between models; the relative evidence of model 1 was only 1.5 times more likely of being true than model 4 (Table 1). The most common variable in the models (present in three of four) was average monthly wet season rainfall during gestation. Other variables associated with $P$. edwardsi birth rate, in the order of most important (based on relative weights), were the number of months with extreme rainfall (>550 mm) during gestation, cyclone landfall during gestation, and ENSO phase the year preceding conception/gestation (Table 2). The variables not found in the supported models were ENSO phase affecting gestation, number of months of below average dry season
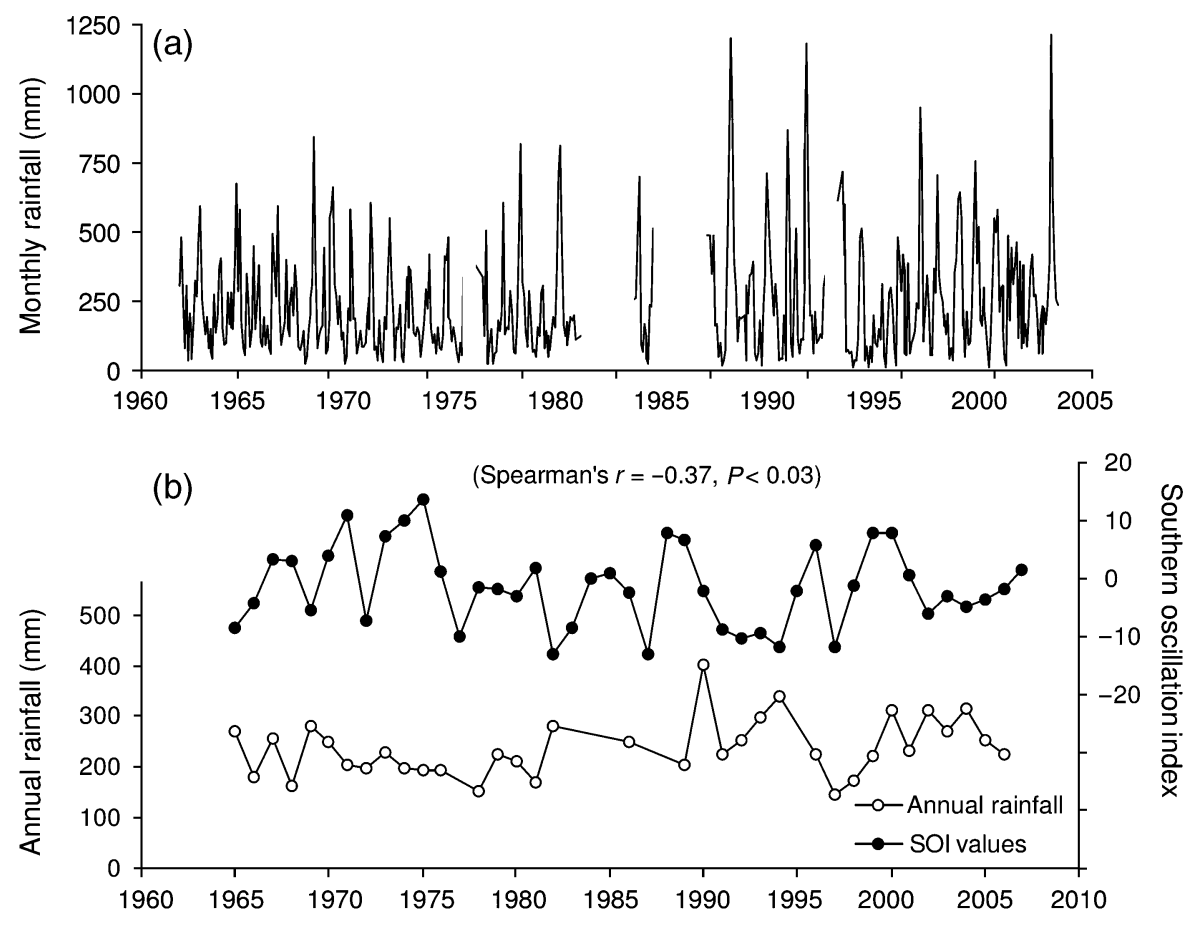

Fig. 1 (a) Monthly averages of rainfall in Ranomafana region from 1965 to 2006. Increasing rainfall and variability in rainfall are apparent. (b) Annual rainfall levels and Southern Oscillation Index values from 1965 to 2006, yield a significant negative correlation. 


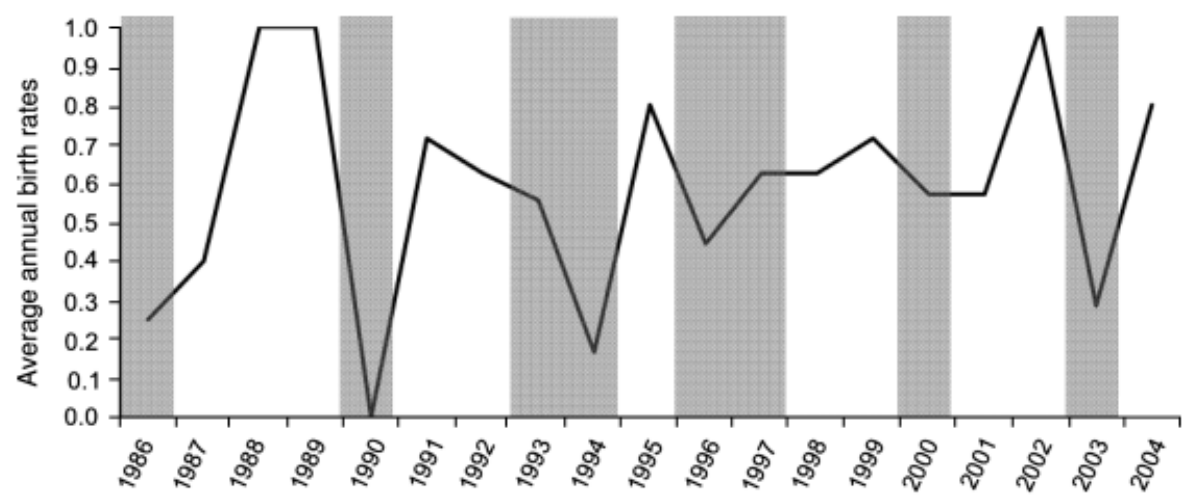

Fig. 2 Cyclone presence (indicated by gray bars) is negatively associated with average yearly birth rates of Propithecus edwardsi females.

Table 1 Generalized linear models of (a) birth rate (b) first year survival and (c) overall lemur fecundity, using best subsets (AIC $)$

\begin{tabular}{|c|c|c|c|c|c|}
\hline Model & & & $R^{2}$ & $\Delta \mathrm{AIC}_{\mathrm{c}}$ & $w_{i}$ \\
\hline \multicolumn{6}{|l|}{ (a) Birth rate } \\
\hline 1 ENSO phase (A) & Wet season rainfall $(G)$ & $\begin{array}{l}\text { Months of } \\
\text { extreme rain }(G)\end{array}$ & 0.79 & 0.00 & 0.17 \\
\hline 2 Wet season rainfall $(G)$ & & & 0.47 & 0.08 & 0.16 \\
\hline 3 Cyclone presence $(G)$ & & & 0.44 & 0.75 & 0.11 \\
\hline 4 Wet season rainfall $(G)$ & Months of extreme rain $(G)$ & & 0.62 & 0.86 & 0.11 \\
\hline \multicolumn{6}{|l|}{ (b) First year survival } \\
\hline 1 Months of drought $(L)$ & & & 0.27 & 0.00 & 0.20 \\
\hline 2 Cyclone presence $(L)$ & & & 0.23 & 0.53 & 0.15 \\
\hline 3 ENSO phase $(C)$ & & & 0.22 & 0.59 & 0.15 \\
\hline 4 ENSO phase $(B)$ & & & 0.12 & 1.75 & 0.08 \\
\hline \multicolumn{6}{|l|}{ (c) Fecundity } \\
\hline 1 ENSO phase $(C)$ & Cyclone presence $(G)$ & & 0.80 & 0.00 & 0.40 \\
\hline 2 ENSO phase $(C)$ & ENSO phase $(A)$ & Cyclone (G) & 0.84 & 1.97 & 0.15 \\
\hline
\end{tabular}

Only models with considerable support $\left(\Delta \mathrm{AIC}_{\mathrm{c}} \leq 2\right)$ are shown. $\Delta \mathrm{AIC}_{\mathrm{c}}$ represents differences in model scores relative to the best model ( 0 has most support; values between 0 and 2 have substantial support; values $>2$ have considerably less support). $w_{i}$ represents Akaike model weights.

$(G)$ after a variable represents that occurring during gestation and $(L)$ represents that occurring during lactation. ENSO phase $(A)=$ ENSO conditions (see Materials and Methods) during the year before conception. ENSO phase $(B)=$ ENSO conditions affecting gestation and the first 6 months of life and ENSO phase $(C)=$ ENSO conditions affecting the second 6 months of life. See methods for description of other variables. For fecundity only those variables that were found in the best models $\left(\Delta\right.$ AIC $\left.C_{c} \leq 2\right)$ for birth rate and first year survival were used [listed under (a) and (b)].

rain during gestation, and average monthly dry season rainfall during gestation.

\section{First year survival}

Four models of first year survival, consisting of single climatic variables received considerable relative support $\left(\Delta \mathrm{AIC}_{\mathrm{c}}<2\right)$, with a 2.5 times difference in evidence ratios between models 1 and 4 (Table 1). The model containing the variable, number of months of drought during lactation, was ranked best for describing variation in first year survival, followed in order by cyclone presence during lactation, ENSO phase during the second 6 months of life, and ENSO phase affecting gestation and the first 6 months of life (Table 2). Models containing dry season rainfall, wet season rainfall and months of extreme rainfall $(>550 \mathrm{~mm})$ were not supported in describing first year survival.

\section{Overall fecundity}

As in a related study (Dunham et al., 2008), fecundity of P. edwardsi was found to be lower when the second 6 months of life coincided with the warmer phases of ENSO (Spearman's $P=0.55, \mathrm{df}=19, P=0.01$ ); in other words, during El Niño years fecundity was significantly 
Table 2 Relative weighted importance $\left(w_{i}\right)$ of variables predicting fecundity and its subcomponents

\begin{tabular}{|c|c|c|c|c|c|c|c|c|}
\hline & \multicolumn{2}{|c|}{ Birth rate } & & \multicolumn{2}{|c|}{ First year survival } & & \multicolumn{2}{|c|}{ Fecundity } \\
\hline & $w_{i}$ & $\begin{array}{l}\text { Estimated } \\
\text { coefficient }\end{array}$ & & $w_{i}$ & $\begin{array}{l}\text { Estimated } \\
\text { coefficient }\end{array}$ & & $w_{i}$ & $\begin{array}{l}\text { Estimated } \\
\text { coefficient }\end{array}$ \\
\hline Wet season rain $(G)$ & 0.67 & -1.52 & Months of drought $(L)$ & 0.31 & -1.11 & Cyclone presence $(G)$ & 0.94 & -0.59 \\
\hline $\begin{array}{l}\text { Months of extreme } \\
\text { rain }(G)\end{array}$ & 0.37 & 1.2 & Cylone presence $(L)$ & 0.25 & -0.026 & ENSO phase $(C)$ & 0.92 & 0.54 \\
\hline $\begin{array}{l}\text { Cyclone } \\
\text { presence }(G)\end{array}$ & 0.28 & -0.23 & ENSO phase $(C)$ & 0.21 & 0.576 & ENSO phase $(A)$ & 0.23 & 0.42 \\
\hline ENSO phase $(A)$ & 0.24 & 0.4 & ENSO phase $(B)$ & 0.15 & -0.54 & & & \\
\hline
\end{tabular}

$w_{i}$ was calculated by summing weights across all models in which variables occurred (higher values signify higher importance to a maximum of 1). The estimated value for the standardized coefficient of each variable are also shown. Variables with $w_{i}>0.5$ are shown in bold.

See Table 1 for symbol explanation.

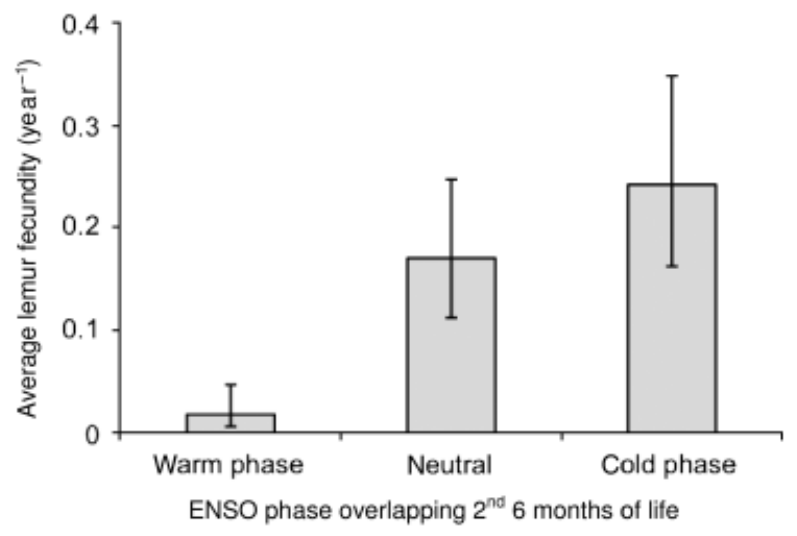

Fig. 3 Fecundity rate of Propithecus edwardsi females relative to warm, normal and cold phases of El Niño Southern Oscillations (ENSO) defined according to the Japan Meteorological Agency (JMA) index. Error bars represent standard errors.

lower than non-El Niño years (GLM, $F_{1,16}=5.5$, $P<0.02$ ) (Fig. 3). When using all variables that best described the subcomponents of fecundity (see Table $2)$, two models were given considerable relative support $\left(\Delta \mathrm{AIC}_{\mathrm{c}}<2\right)$ for describing overall fecundity rates. The ENSO phase affecting the offspring's second 6 months of life (Fig. 3) and the presence of cyclones during gestation were found in both models and the second model also included the ENSO phase preceding conception/gestation. There was a 2.7 times difference between the two models. The relative weighted importance of both cyclone presence and ENSO phase affecting the second 6 months of life were quite high (0.93 and 0.92 , respectively) and very similar to each other, whereas the ENSO phase preceding conception/ gestation received a much lower relative weight (0.23, Table 2).

\section{Discussion}

There is a growing body of evidence that climate change is affecting global species diversity and survival (Sala et al., 2000; Williams et al., 2003; Thomas et al., 2004; Cheung et al., 2009). Recent studies have concluded that even in tropical areas, where rampant deforestation and exploitation already threaten wildlife, species are facing additional grave threats from our world's changing climate (Malhi \& Wright, 2004). However, regions such as Madagascar, which are rich in biodiversity but may have low adaptive capacity to climatic change, are poorly represented in studies examining the effects of climate variability on biota (Felton et al., 2009; but see Raxworthy et al., 2008; Lawler et al., 2009). Using P. edwardsi as an example, we show that species living in tropical forests may also be extremely vulnerable to changes in climate and the landfall of cyclones. We present the first evidence, we are aware of, that links regional rainfall variation in Madagascar's southeastern rainforest with global climate cycles and to link these variables and cyclones with variations in fecundity, a key demographic parameter in an endangered primate.

\section{ENSO and climate variability in Madagascar's southeastern rainforest}

Wet season rainfall intensity and the number of dry season months with below average rainfall during the critical lactation season were both associated with the SOI, with warmer cycles associated with more rain and more months of extreme rain, and colder cycles associated with below average dry season rainfall in the following year. These results are contrary to that found in southern Africa where, in general, El Niño brings drought and La Nina brings rain (Mason \& Jury, 1997). Previous work on the 
relationship between ENSO and precipitation in Madagascar has supported our findings, by suggesting an inverse relationship from that in southern Africa (Jury \& Pathack, 1991; Jury et al., 1995; Brook et al., 1999), however, the pattern may vary within Madagascar as other studies have found that El Niño years in Madagascar are followed by drought conditions and increased fire prevalence (Ingram \& Dawson, 2005). Larger scale studies beyond the local scale are necessary to quantify how ENSO impacts various regions throughout Madagascar.

\section{Climate and demography}

Our study of demography in a wild P. edwardsi population suggests that their reproductive rates are affected by cyclone landfall, ENSO phases and rainfall levels. Overall fecundity (defined as the number of offspring per female per year surviving to 1 year of age) was negatively associated with cyclone presence during gestation, and positively associated with colder ENSO phases during the second 6 months of life and during the period faced by mothers preceding conception. Additionally, wet season rainfall and intensity during gestation was negatively related to birth rates, whereas the number of drought months during lactation was negatively associated with first year survival.

Cyclones had the strongest overall impact on P. edwardsi fecundity rates. Cyclones in Madagascar run from December through April, overlapping with the gestation period of P. edwardsi (Wright, 1999). Although cyclones are a natural part of Madagascar's environment and are important for regeneration of several tree species (Ganzhorn, 1995), temporary effects of cyclones have been suggested to negatively affect wildlife populations. Anecdotal evidence from costal forest has suggested that severe cyclones in Malagasy rainforest can dramatically reduce leaf and fruit resources available to lemurs resulting in nutritional stress (Ratsimbazafy, 2006) increased mortality and reduced or absent birth rates of lemurs (Ratsimbazafy, 2002). Negative impacts of cyclone landfall on fruit availability have also been shown in our study area. Erhart \& Overdorff (2008a) documented that the percentage of large trees bearing fruit dropped strongly after cyclone landfall, with some cyclones leaving no fruit (after cyclone Alibera, Category 4 ) to only $1 \%$ remaining (cyclone Manao, Category 2). Our current study is the first that we are aware of to suggest, based on nonanecdotal accounts that cyclones can exert strong influence on the population dynamics of a long-lived primate species through reductions in fecundity, affecting both birth rates and first year survival. Not all lemurs in the region may be similarly affected by cyclone landfall, however. Erhart \& Overdorff (2008a) found that birth rate did not differ for
Eulemur fulvus rufus in Ranomafana between cyclone/ tropical storm and nonstorm years (Kendall Rank Correlation: $\tau=0.24, Z=0.75, P=0.45$ ), however, the sample size of adult females each year for that study ranged between only one and four individuals.

$P$. edwardsi reproduction was also associated with ENSO phase, which was reflected in all parameters. This suggests that Madagascar's wildlife may be sensitive to changes in global climate cycles despite their tropical latitude. Warm phases, associated with heavy rains in the region resulted in lower fecundities for P. edwardsi. Fecundity was negatively affected when a warm El Niño phase occurred in the period before conception, perhaps altering ovulation, or during the second 6 months of life, possibly reducing infant survival during weaning. The negative association of fecundity with periods of heavy rains was unexpected. In a previous study (Dunham et al., 2008) we hypothesized that the negative effect of ENSO on lemur reproduction was possibly caused by drought, although a complete rainfall database was not available at the time. However, in rainforest habitat, extreme rainfall events have been shown to cause stress to tree stands (Akashi \& Mueller-Dombois, 1995), which, in this case, may reduce tree resources available to the lemurs. In other tropical forests, both intense drought and intense rainfall caused by ENSO phases have been demonstrated to negatively affect forest vegetation and even cause increased tree mortality (see Lewis et al., 2004). Further research is needed to determine relationships of wet season rainfall on forest phenology and time lemurs spend foraging in this system.

We had expected that drought would be one of the most important factors likely to threaten $P$. edwardsi populations in the face of climate variability (Wright, 2006; Dunham et al., 2008) based on suggestions of prior studies (Gould et al., 1999; Richard et al., 2000; King et al., 2005). Population growth rates of the closely related Verreaux's sifaka (Propithecus verrauxi), inhabiting southern dry forests, have been found to be most sensitive to drought conditions (Lawler et al., 2009). In RNP, King et al. (2005) demonstrated that aging P. edwardsi females with senescent teeth had little success raising young especially in years with dry lactation seasons. Drought during lactation in the present study was negatively associated with first year survival but with relatively low weighted importance (Table 2), and was not associated with fecundity overall, suggesting that at current levels, it is unlikely to have much effect on population dynamics. However, if increasing variability in rainfall leads to more frequent and drier extremes during lactation periods, young mothers may also be affected to a point where overall fecundity is lowered. Extreme drought conditions such as that found in Madagascar's dry forests appear to be less 
common in rainforest environments. For example, a prolonged drought experienced by ring-tailed lemurs (Lemur catta) in the dry forest of southwestern Madagascar in 1991 and 1992 caused sharp population declines due to dramatic increases in mortality (Gould et al., 1999). Similar drought conditions have not been experienced in the southeastern rainforest during the time period of our study and it is likely that species found in different biomes of Madagascar will be differentially affected by climatic variables.

\section{Conclusions}

Our results suggest an important association of lemur reproduction with both cyclone landfall and climatic variability indicating climatic changes may be an additional threat to Madagascar's already endangered flora and fauna. The link of climatic conditions with ENSO in this study suggests that dynamics of wildlife populations even in tropical areas such as Madagascar can be affected by global climate cycles making them potentially vulnerable to global climate change. It is unclear if the association of ENSO and local rainfall we found in this study applies to the island as a whole or is more complicated. Further research into the trends and predictions of changing climate patterns across Madagascar and the influence of climate on wildlife could greatly aid future conservation efforts. Current predictions of climate change in Madagascar, including wetter wet seasons and drier dry seasons (Hannah et al., 2008), could have negative consequences on the demography of lemurs and other wildlife. Our results suggest that conservation strategies in Madagascar may require consideration of not only the direct impact of anthropogenic activities such as hunting and deforestation, but also of how the outcomes of these activities may be compounded by influences of the world's changing climate.

\section{Acknowledgements}

We thank Madagascar's ANGAP, Department of Water and Forests, Ministry of the Environment, Water, Forests and Tourism, and the CAFF/CORE committee for authorization to do this research. Thanks to B. Andriamihaja and A. Feistner and staffs of MICET, Centre ValBio, and ICTE for logistical support. Funding for the long-term monitoring of lemurs was provided from the David and Lucile Packard Foundation, Douroucouli Foundation, Wenner-Gren Foundation, John D. and Catherine T. MacArthur Foundation, National Geographic Society, National Science Foundation, Earthwatch Institute, Conservation International, Margot Marsh Biodiversity Foundation, Stony Brook University and Rice University. We acknowledge ValBio's many dedicated field assistants for lemur observations and for collecting climate data. Thanks to Drs J. Jernvall, J. Ratsimbazafy and V. Rudolf for invaluable discussion and comments.

\section{References}

Adahl E, Lundberg P, Jonzen N (2006) From climate change to population change: the need to consider annual life cycles. Global Change Biology, 12, 1627-1633.

Akashi Y, Mueller-Dombois D (1995) A landscape perspective of the Hawaiian rain forest dieback. Journal of Vegetation Science, 6, 449-464.

Bence JR (1995) Analysis of short time series: correcting for autocorrelation. Ecology, 76, 628-639.

Brook GA, Rafter MA, Railsback LB, Sheen SW, Lundberg J (1999) A high-resolution proxy record of rainfall and ENSO since AD 1550 from layering in stalagmites from Anjohibe Cave, Madagascar. The Holocene, 9, 695.

Brooks TM, Mittermeier RA, Mittermeier CG et al. (2002) Habitat loss and extinction in the hotspots of biodiversity. Conservation Biology, 16, 909.

Burnham KP, Anderson DR (2002) Model Selection and Multimodel Inference: A Practical Information-Theoretic Approach. Springer-Verlag, New York, NY, USA

Caswell H (2001) Matrix Population Models: Construction, Analysis, and Interpretation. Sinauer, Sunderland, MA.

Chelton DB (1984) Commentary: short-term climatic variability in the northeast Pacific Ocean. In: The Influence of Ocean Conditions on the Production of Salmonids in the North Pacific (ed. Pearcy W), pp. 87-99. Oregon State University Press, Corvallis, OR.

Cheung WWL, Lam VWY, Sarmiento JL, Kearney K, Watson R, Pauly D (2009) Projecting global marine biodiversity impacts under climate change scenarios. Fish and Fisheries, 10, 235-251.

COAPS (2008). Center for Ocean-Atmospheric Prediction Studies. Available at: http://www.coaps.fsu.edu/ legler/jma_index1.shtml (accessed 20 November 2009).

Dixon RK, Smith J, Guill S (2003) Life on the edge: vulnerability and adaptation of African ecosystems to global climate change. Mitigation and Adaptation Strategies for Global Change, 8, 93-113.

Dunham AE, Erhart EM, Overdorff DJ, Wright PC (2008) Evaluating effects of deforestation, hunting, and El Nino events on a threatened lemur. Biological Conservation, 141, 287-297.

Dunham AE, Rudolf VHW (2009) Evolution of sexual size monomorphism the influence of passive mate guarding. Journal of Evolutionary Biology, 22, 1376-1386.

Erhart EM, Overdorff DJ (1998) Infanticide in Propithecus diadema edwardsi: an evaluation of the sexual selection hypothesis. International Journal of Primatolgy, 19, 73-81.

Erhart EM, Overdorff DJ (2008a) Population demography and social structure changes in Eulemur fulvus rufus from 1988 to 2003. American Journal of Physical Anthropology, 136, 183.

Erhart EM, Overdorff DJ (2008b) Spatial memory during foraging in prosimian primates: Propithecus edwardsi and Eulemur fulvus rufus. Folia Primatologica, 79, 185-196.

Felton A, Fischer J, Lindenmayer DB et al. (2009) Climate change, conservation and management: an assessment of the peer-reviewed scientific journal literature. Biodiversity and Conservation, 18, 2243-2253.

Ganzhorn JU (1995) Cyclones over Madagascar: fate or fortune? Ambio, 24, 124-125.

Gould L, Sussman RW, Sauther ML (1999) Natural disasters and primate populations: the effects of a 2-year drought on a naturally occurring population of ring-tailed lemurs (Lemur catta) in southwestern Madagascar. International Journal of Primatology, 20, 69-84.

Hanley DE, Bourassa MA, O'Brien JJ, Smith SR, Spade ER (2003) A quantitative evaluation of ENSO indices. Journal of Climate, 16, 1249-1258.

Hannah L, Dave R, Lowry PP et al. (2008) Climate change adaptation for conservation in Madagascar. Biology Letters, 4, 590-594.

Harper GJ, Steininger MK, Tucker CJ, Juhn D, Hawkins F (2008) Fifty years of deforestation and forest fragmentation in Madagascar. Environmental Conservation, 34, 325-333.

Harris PP, Huntingford C, Cox PM (2008) Amazon Basin climate under global warming: the role of the sea surface temperature. Philosophical Transactions of the Royal Society B: Biological Sciences, 363, 1753.

Huntingford C, Fisher RA, Mercado L et al. (2008) Towards quantifying uncertainty in predictions of Amazon 'dieback'. Philosophical Transactions of the Royal Society B: Biological Sciences, 363, 1857.

Ingram JC, Dawson TP (2005) Climate change impacts and vegetation response on the island of Madagascar. Philosophical Transactions of the Royal Society. Mathematical, $363,55-59$.

Irwin MT, Johnson SE, Wright PC (2005) The state of lemur conservation in southeastern Madagascar: population and habitat assessments for diurnal and cathemeral lemurs using surveys, satellite imagery and GIS. Oryx, 39, 204-218. 
Jury MR (2003) The climate of Madagascar. In: The Natural History of Madagascar (eds Goodman SM, Benstead JP), pp. 75-86. University of Chicago Press, Chicago, IL.

Jury MR, Parker BA, Raholijao N, Nassor A (1995) Variability of summer rainfall over Madagascar: climatic determinants at interannual scales. International Journal of Climatology, 15, 1323-1332.

Jury MR, Pathack B (1991) A study of climate and weather variability over the tropical southwest Indian Ocean. Meteorology and Atmospheric Physics, 47, 37-48.

King SJ, Arrigo-Nelson SJ, Pochron ST, Semprebon GM, Godfrey LR, Wright PC, Jernvall J (2005) Dental senescence in a long-lived primate links infant survival to rainfall. Proceedings of the National Academy of Sciences, 102, 16579-16583.

Klein SA, Soden BJ, Lau NC (1999) Remote sea surface temperature variations during ENSO: evidence for a tropical atmospheric bridge. Journal of Climate, 12, 917-932.

Kremen C, Cameron A, Moilanen A et al. (2008) Aligning conservation priorities across taxa in Madagascar with high-resolution planning tools. Science, 320, 222.

Latif M, Keenlyside NS (2009) El Nino/Southern Oscillation response to global warming. Proceedings of the National Academy of Sciences of the United States of America, 106, 20578-20583.

Lau NC, Nath MJ (2003) Atmosphere-ocean variations in the Indo-Pacific sector during ENSO episodes. Journal of Climate, 16, 3-20.

Lawler RR, Caswell H, Richard AF, Ratsirarson J, Dewar RE, Schwartz M (2009) Demography of Verreaux's sifaka in a stochastic rainfall environment. Oecologia, 161, 491-504.

Lehman SM, Rajaonson A, Day S (2006) Edge effects and their influence on lemur density and distribution in southeast Madagascar. American Journal of Physical Anthropology, 129, 232-241.

Lehman SM, Ratsimbazafy J, Rajaonson A, Day S (2005) Decline of Propithecus diadema edwardsi and Varecia variegata variegata (Primates: Lemuridae) in south-east Madagascar. Oryx, 40, 108-111.

Lewis SL, Malhi Y, Phillips OL (2004) Fingerprinting the impacts of global change on tropical forests. Philosophical Transactions of the Royal Society B, 359, 437-462.

Malhi Y, Wright J (2004) Spatial patterns and recent trends in the climate of tropical rainforest regions. Philosophical Transactions of the Royal Society B Biological Sciences, 359, 311-329.

Marchant R, Hooghiemstra H (2004) Rapid environmental change in African and South American tropics around 4000 years before present: a review. Earth Science Reviews, 66, 217-260.

Mason SJ, Jury MR (1997) Climatic variability and change over southern Africa: a reflection on underlying processes. Progress in Physical Geography, 21, 23.

Meehl GA, Teng H, Branstator G (2006) Future changes of El Niño in two global coupled climate models. Climate Dynamics, 26, 549-566.

Mittermeier RA, Valladares-Pádua C, Rylands $\mathrm{AB}$ et al. (2006) Primates in Peril: the World's 25 Most Endangered Primates, 2004-2006. Primate Conservation, 20, $1-28$.

Morelli TL, King SJ, Pochron ST, Wright PC (2009) The rules of disengagement: takeovers, infanticide, and dispersal in a rainforest lemur, Propithecus edwardsi. Behaviour, 146, 499-523.

Myers N, Mittermeier RA, Mittermeier CG, da Fonseca GAB, Kent J (2000) Biodiversity hotspots for conservation priorities. Nature, 403, 853-858.

Pochron ST, Tucker WT, Wright PC (2004) Demography, life history, and social structure in Propithecus diadema edwardsi from 1986-2000 in Ranomafana National Park, Madagascar. American Journal of Physical Anthropology, 125, 61-72.

Pochron ST, Wright PC (2003) Variability in adult group compositions of a prosimian primate. Behavioral Ecology and Sociobiology, 54, 285-293.

Pyper BJ, Peterman RM (1998) Comparison of methods to account for autocorrelation in correlation analyses of fish data. Canadian Journal of Fisheries and Aquatic Sciences, $55,2127-2140$.
Ratsimbazafy HJ (2002) On the Brink of Extinction and the Process of Recovery: Varecia Variegata Variegata in Manombo Forest. Doctoral dissertation, Stony Brook University, Stony Brook, NY.

Ratsimbazafy J (2006) Diet composition, foraging, and feeding behavior in relation to habitat disturbance: implications for the adaptability of ruffed Lemurs (Varecia variegata editorium) in Manombo forest, Madagascar. In: Lemurs: Ecology and Adaptation, (eds Gould L, Sauther ML), pp. 403-422. Springer, New York, NY.

Raxworthy CJ, Pearson RG, Rabibisoa N et al. (2008) Extinction vulnerability of tropical montane endemism from warming and upslope displacement: a preliminary appraisal for the highest massif in Madagascar. Global Change Biology, 14, 1703-1720.

Richard AF, Dewar RE, Schwartz M, Ratsirarson J (2000) Mass change, environmental variability and female fertility in wild Propithecus verreauxi. Journal of Human Evolution, 39, 381-391.

Sagarin RD, Gaines SD, Gaylord B (2006) Moving beyond assumptions to understand abundance distributions across the ranges of species. Trends in Ecology \& Evolution, 21, 524-530.

Sala OE, Chapin Iii FS, Armesto JJ et al. (2000) Global biodiversity scenarios for the year 2100. Science, 287, 1770.

Shinoda T, Alexander MA, Hendon HH (2004) Remote response of the Indian Ocean to interannual SST variations in the tropical Pacific. Journal of Climate, 17, 362-372.

Sommer S, Hommen U (2001) Modelling the effects of life-history traits and changing ecological conditions on the population dynamics and persistence of the endangered Malagasy giant jumping rat (Hypogeomys antimena). Animal Conservation, 3, 333-343.

Tadross M, Randriamarolaza L, Rabefitia Z, Yip ZK (2008) Climate Change in Madagascar, Recent Past and Future. World Bank, Washington, DC.

Thomas CD, Cameron A, Green RE et al. (2004) Extinction risk from climate change. Nature, 427, 145-148.

Thomson MC, Abayomi K, Barnston AG, Levy M, Dilley M (2003) El Nino and drought in southern Africa. The Lancet, 361, 437-438.

Van Horn RN, Eaton GG (1979) Reproductive Physiology and Behavior in Prosimians. The Study of Prosimian Behavior pp. 79-122. Academic Press, New York.

Venzke S, Latif M, Villwock A (2000) Coupled GCM ECHO-2. Part II: Indian Ocean response to ENSO. Journal of Climate, 13, 1371-1383.

Walther GR, Post E, Convey P et al. (2002) Ecological responses to recent climate change. Nature, 416, 389-395.

Whitmore TC (2000) Madagascar deforestation rate during 1980. In: Biogeography of Madagascar (eds Lourenco WR, Goodman SM), Mémoires de la Société de Biogéographie, Paris.

Whittingham MJ, Stephens PA, Bradbury RB, Freckleton RP (2006) Why do we still use stepwise modelling in ecology and behaviour? Ecology, 75, 1182-1189.

Williams SE, Bolitho EE, Fox S (2003) Climate change in Australian tropical rainforests: an impending environmental catastrophe. Proceedings of the Royal Society B: Biological Sciences, 270, 1887.

Wright PC (1995) Demography and life history of free-ranging Propithecus diadema edwardsi in Ranomafana National Park, Madagascar. International Journal of Primatology, 16, 835-854.

Wright PC (1999) Lemur traits and Madagascar ecology: coping with an island environment. Yearbook of Physical Anthropology, 42, 31-72.

Wright PC (2006) Considering climate change effects in lemur ecology and conservation. In: Lemurs: Ecology and Adaptation (eds Gould L, Sauther ML), pp. 387-404. Springer, New York, NY.

Wright PC, Andriamihaja B (2002) Making a rain forest work in Madagascar. In: Making Parks Work: Strategies for Preserving Tropical Nature (eds Terborgh J, Van Schaik C, Davenport L, Rao M), pp. 112-136. Island Press, Washington, DC. 